ESTUDIOS

\title{
Reforma laboral en Brasil: la supremacía convencional y la protección de los derechos humanos a cargo del poder judicial
}

\author{
Labour reform in brazil: the conventional supremacy \\ and the duty of protection of human rights for the judiciary
}

\section{Tiago Muniz Cavalcanti}

Escola Superior do Ministério Público da União, Brasil

Juliana Teixeira Esteves

Universidade Federal de Pernambuco, Brasil

\begin{abstract}
RESUMEN Brasil pasa por un momento de crisis política e institucional y de adopción de políticas corrosivas a los derechos humanos. Más que nunca, el poder judicial laboral debe ejercer el papel de guardián de estos derechos y de protector del postulado de la dignidad de la persona trabajadora. Este artículo tiene como objetivo principal analizar el control difuso de convencionalidad como instrumento de protección de los derechos humanos y, sobre todo, examinar la conformidad de la denominada «reforma laboral» con los tratados y convenciones internacionales. Por medio del estudio de las decisiones de la Corte Interamericana de Derechos Humanos, la investigación demuestra que es deber del poder judicial proteger y hacer efectivos los derechos humanos, sobre todo en momentos de violación por el legislativo con el sello del ejecutivo.
\end{abstract}

PALABRAS CLAVE Derechos humanos; derechos laborales; protección; reforma laboral; control difuso de convencionalidad.

ABSTRACT Brazil is going through a moment of political and institutional crisis and the adoption of corrosive policies to human rights. More than ever before, the Labour Judiciary must exercise its role as the guardian of these rights and as the protector of the dignity of the common working person. The main purpose of this article is to analyze the diffuse control of conventionality as an instrument for the protection of the human rights and, above all, to examine the conformity of the so-called «labour reform « with international treaties and conventions. Through the study of the decisions of the InterAmerican Court of Human Rights, the research shows that it is the duty of the judiciary 
to protect and to make effective human rights, especially in times of discredit and uncertainty by the Legislative with the consent of the Executive.

KEYWORDS Human rights; labour rights; protection; labour reform; diffuse control of conventionality.

\section{Introducción}

Los derechos humanos deben ser respetados, promovidos y protegidos. Esto genera que el Estado, principal destinatario y guardián de estos derechos, tenga la obligación de no actuar de forma contraria a los derechos humanos, realizarlos por medio de la implementación de políticas públicas y, sobre todo, protegerlos, garantizando su libre y pleno ejercicio.

Este deber de protección se extiende a todos los órganos estatales y poderes públicos, incluso al legislativo. Durante el proceso de producción de leyes, al legislador le incumbe salvaguardar los derechos humanos mediante el análisis de la conformidad de la norma con los tratados y convenciones internacionales.

Sin embargo, de vez en cuando, la edición de las leyes deja de servir a la promoción y protección de los derechos humanos y pasa a confrontarlos. En estos casos, le corresponde a los demás agentes del Estado adoptar medidas necesarias de cualquier naturaleza para hacerlos efectivos, reprimiendo las violaciones provocadas por el proceso legislativo. Surge, entonces, el control difuso de convencionalidad de las leyes a cargo de los jueces y tribunales brasileños.

La finalidad de este trabajo es estudiar el papel del poder judicial en el sentido de proteger los derechos humanos de los trabajadores frente a los retrocesos resultantes de las reformas precarizantes, dejando de aplicarlas al caso concreto. Este deber del magistrado es derivado del principio de la supremacía convencional.

En efecto, examinaremos la reciente modificación normativa laboral en Brasil y su compatibilidad o incompatibilidad con el derecho internacional de trabajo, tomando como parámetro los convenios de la Organización Internacional del Trabajo ratificados por el país que apuntan a la promoción del trabajo decente, además de otros instrumentos dirigidos a la protección, progresividad y la plena efectividad de los derechos laborales. Además, será muy importante para los objetivos del presente estudio el examen de los precedentes jurisprudenciales que, acogiendo la tesis de la suprarregulación de los tratados y convenciones sobre derechos humanos, reconocen el efecto paralizante de las normas internas en desacuerdo con los compromisos internacionales. 


\section{Los derechos humanos laborales}

No se niega, o al menos se niega poco, que los derechos humanos son los derechos más importantes de las personas, esenciales en la afirmación de la dignidad y que garantizan un mínimo de civilidad al titular. ${ }^{1}$ A este elemento material, sin embargo, se debe añadir un elemento eminentemente formal, es decir, el reconocimiento jurídico. ${ }^{2}$ Es precisamente en el aspecto formal, específicamente en el plan de positivización, que reposa el elemento diferenciador de los derechos humanos en relación con los derechos fundamentales: mientras estos son reconocidos y positivizados en el sistema constitucional interno de cada Estado, los otros están previstos en instrumentos internacionales. ${ }^{3}$

Por lo tanto, los derechos humanos garantizan las necesidades básicas de las personas, relacionadas con la dignidad, la libertad y la igualdad, previstas en declaraciones y convenciones internacionales (Pérez Luño, 2013: 39-40), y reflejan posiciones jurídicas universalmente reconocidas al ser humano en carácter supranacional (Wolfgang Sarlet, 2004). En efecto, los derechos humanos laborales consisten en la consagración universal de derechos que protegen al ser humano como trabajador, es decir, al ciudadano inserto en una relación de trabajo o empleo.

En el sentido más amplio de la expresión, los derechos humanos laborales representan el ideal de inclusión social para ofrecer a todos los trabajadores un nivel mínimo de ciudadanía y dignidad. Positivizados inicialmente en el siglo XIX, a partir de las transformaciones sociales causadas por un Estado ausente en la promoción de la justicia social, los derechos humanos laborales se consagraron universalmente en la primera mitad del siglo XX.

De esta característica universal surgen dos funciones esenciales de los derechos humanos laborales: la de inspirar e inducir los sistemas jurídicos internos, como un referencial ético de alcance global, así como completando sus lagunas; y la de parámetro de protección cuando las instituciones nacionales muestran fallas en su deber de promoverlos y protegerlos.

1. En ese sentido, véase Abrantes (2005); Cançado Trindade (1997); Gomes Canotilho (1998); Lafer (2005); Leite Sampaio (2010); Mazetto Ferreira (2007); Paula Amaral (2007); Piovesan (2006); Rezek (2007); Serrano Nunes Júnior (2009); Wolfgang Sarlet (2004).

2. La opción de los autores por una concepción positivista de los derechos humanos no pretende desmerecer la relevancia de teorías no positivistas, pensadas incluso por religiosos y jusnaturalistas que valoran doctrinas morales y textos sagrados, en ausencia del reconocimiento por el derecho.

3. Los derechos humanos están reconocidos tanto en la Declaración Universal de 1948 como en las costumbres, en los principios jurídicos y en los tratados internacionales. Los derechos fundamentales están positivamente en los ordenamientos internos de cada Estado, especialmente en sus constituciones. Es decir, ni todo derecho fundamental puede ser considerado un derecho humano, ni todo derecho humano puede ser considerado un derecho fundamental (Bezerra Leite, 2011). 
Estas funciones de sustancia y protección ejercidas por los derechos humanos laborales en el orden interno tienen el propósito de mitigar la disponibilidad de los poderes constituidos, sea como una influencia exógena que induzca los más diversos ordenamientos jurídicos o como referencia normativa que limita la acción de los órganos estatales.

\section{La supralegalidad de los derechos humanos laborales}

La omisión de la Constitución de Brasil con respecto a la jerarquía de los tratados internacionales al momento de su ingreso al ordenamiento jurídico brasileño, hizo surgir discusiones doctrinales y jurisprudenciales que ganan contornos todavía más dramáticos cuando los tratados se refieren a los derechos humanos.

Algunos autores defendían la jerarquía infraconstitucional equiparada a las leyes federales, sobre todo con base en el artículo 102 3b de la Constitución brasileña, que atribuye a la Suprema Corte la competencia para juzgar las causas decididas en única o última instancia en el caso de que la decisión impugnada declare la inconstitucionalidad de tratado o ley federal. Este sería el fundamento constitucional para conferir idéntica jerarquía jurídica de las leyes federales a los tratados internacionales. La equiparación a las leyes haría posible, por lo tanto, la aplicación de la tradicional regla de revocación de las leyes: la posterior revoca la anterior cuando expresamente lo declare, cuando sea incompatible o cuando regule enteramente la materia de que trataba la ley anterior, en los términos del artículo 2 sección 1 de la Ley de Introducción a las normas del derecho brasileño.

Otros juristas visualizaban en estos tratados una jerarquía constitucional, principalmente por la naturaleza especial y diferenciada derivada de la cláusula de apertura contenida en el artículo 5 sección 2, según el cual los derechos y garantías expresados en la Constitución no excluyen otros derivados del régimen y de los principios adoptados por ella, o de los tratados internacionales en que la República Federal del Brasil sea parte. Esta cláusula constitucional de apertura representa un reconocimiento de incompletitud, posibilitando, por lo tanto, su integración y complementación mediante los derechos internacionales. Es decir, los principios y derechos constantes en los tratados internacionales complementan la carta de derechos y garantías prevista en el texto constitucional.

En ese sentido, mientras los tratados internacionales comunes tienen fuerza jerárquica infraconstitucional, los derechos enunciados en tratados internacionales de protección de los derechos humanos presentan valor de norma constitucional. Esto ocurre porque si los primeros buscan el equilibrio y la reciprocidad de relaciones entre los Estados partes, los segundos trascienden estos meros compromisos recíprocos entre los Estados pactantes y objetivan salvaguardar los derechos del ser humano (Piovesan, 2006: 59). 
Las discusiones doctrinales no tuvieron fin con la sobrevenida de la sección 3 al artículo 5 en el marco de la reforma constitucional por medio de la enmienda constitucional número 45 de 8 de diciembre de 2004, diciendo que los tratados y convenciones internacionales sobre derechos humanos que sean aprobados, en cada casa del Congreso Nacional, en dos turnos, por tres quintas partes de los votos de sus miembros, serán equivalentes a las enmiendas constitucionales. Permanecía la duda con respecto a los tratados de derechos humanos incorporados al ordenamiento jurídico interno antes de la promulgación de dicha enmienda, así como en relación con los incorporados en un momento posterior sin el quórum cualificado previsto en el texto constitucional.

El debate hizo surgir una corriente intermedia que ganó fuerza en la doctrina y en la jurisprudencia. Reconociendo en los tratados internacionales un estatus supralegal, la tesis se alía en el principio de la buena fe internacional, insertado en el artículo 27 de la Convención de Viena: «una parte no podrá invocar las disposiciones de su derecho interno como justificación del incumplimiento de un tratado». Además, admitir la revocación de tratados internacionales de los que el país es parte supone desprestigiar el principio de la buena fe internacional, en específico en lo que respecta al pacta sunt servanda (Muniz Cavalcanti, 2016). En efecto, de acuerdo con la teoría de la supralegalidad, los tratados de derechos humanos tienen jerarquía inferior a la Constitución, pero superior a las normas infraconstitucionales.

El Supremo Tribunal Federal de Brasil, que aún no alcanza un nivel deseado en relación con la protección de los derechos humanos, ha privilegiado algunos tratados de derechos humanos frente a la legislación infraconstitucional interna, como ocurrió en el juicio sobre la cuestión del depositario infiel (RE 466.343), ocasión en que la Corte Suprema demostró inclinación hacia la tesis de la supralegalidad.

De acuerdo con su actual entendimiento, el Supremo Tribunal Federal instituyó la «teoría del doble estatus» (o «doble estatuto»). Así, tratados internacionales de derechos humanos aprobados mediante el quórum especial de las enmiendas constitucionales (sección 3 del artículo 5 de la Constitución Federal) tienen jerarquía constitucional; y los demás ostentan estatus supralegal (Beltramelli Neto, 2017: 273). En este caso, los tratados y convenciones internacionales que versan sobre derechos humanos, lo que incluye, evidentemente, los instrumentos de la Organización de las Naciones Unidas y de la Organización Internacional del Trabajo dirigidos a la tutela del ser humano, del trabajo libre, seguro y decente, ratificados por la República Federativa del Brasil, tienen estatus superior a las leyes federales y no pueden ser revocados, negados y/o contrariados por ellas. 


\section{El deber de protección de los derechos humanos y el control difuso de convencionalidad}

Aunque la tradicional clasificación de los derechos humanos los subdivida en grupos apartados conforme a las fases del proceso de reconocimiento y positivización a lo largo de la historia de la humanidad - la primera, segunda y tercera generación- ${ }^{4}$ no se puede perder de vista que todos ellos, ya sean individuales, sociales o difusos, tienen la misma naturaleza y merecen, en efecto, idéntica valoración jurídica.

A pesar de la hegemonía de los derechos humanos como discurso universal de la protección a la dignidad humana es innegable que, en la práctica, la gran mayoría de la población mundial no goza de ellos. La deficiencia en el cumplimiento de los derechos humanos y todos sus productos se ha agravado en tiempos recientes con la crisis global del proyecto de modernidad. Así:

Cada vez somos testigos con más frecuencia de violaciones masivas de los derechos humanos en nombre de los derechos humanos, la destrucción de la democracia en nombre de la democracia, el asesinato de civiles inocentes en el proceso de supuestamente protegerles, la devastación de modos de subsistencia en nombre del desarrollo, la utilización masiva de técnicas de vigilancia y restricciones de las libertades fundamentales en nombre de la preservación de la libertad y la seguridad. Las inversiones ideológicas empleadas en esconder tal discrepancia son tan masivas como la brutalidad de dichas prácticas (Sousa Santos, 2017: 79).

En un contexto de predominio hegemónico del discurso del desarrollo capitalista, los derechos económicos y sociales vienen cediendo cada vez más a las políticas neoliberales: austeridad, privatización, desregulación y flexibilización son verdades incontestables. Esto ocurre en razón de una ideología marcadamente mercantil e individualista que propugna el desmantelamiento de casi todas las formas de presencia e intervención activa del Estado en el sentido de organizar, unificar y garantizar el orden social, incluso mediante la regulación de las actividades económicas.

No se trata solamente de la caída del llamado Estado de bienestar, sino de todo el sistema estatal de conservación y reproducción de la fuerza de trabajo. Esto se agrava por el desmantelamiento de las prestaciones laborales, la intensificación de la jornada laboral, la reducción de los salarios y prestaciones, la flexibilización laboral y

4. El jurista checo Karel Vasak fue quien idealizó la división. En 1979, presentó en el Instituto Internacional de Derechos Humanos en Estrasburgo una clasificación en generaciones en la que buscaba demostrar la evolución de estos derechos. Las generaciones guardan estricta relación con las expresiones libertad, igualdad y fraternidad de la Revolución Francesa: la primera, de los derechos civiles y políticos, encuentran fundamento en la libertad (liberté); la segunda, de los derechos económicos, sociales y culturales, se basa en la idea de igualdad (égalité); la tercera, de los derechos de solidaridad, encontraría su bandera en la fraternidad (fraternité). 
la degradación de todo el ambiente laboral. Todo esto cuestiona los lazos de solidaridad, identidad comunitaria y configuración de valores, modelos de vida y visión de futuro (Correa, 2013: 371).

El neoliberalismo ha penetrado profundamente en las estructuras del derecho del trabajo, debilitando su carácter transaccional hasta el punto de abrogar el pacto originario entre capital y trabajo que hizo posible la convivencia en sociedad. El derecho del trabajo ha involucionado hacia un modelo de intervención débil que responde a la filosofía liberal de ordenación de las relaciones inter privatos (Guamán Hernández e Illueca Ballester, 2012: 35-36). Esto siguió empeorando porque el movimiento de precarización de las formas de trabajo vino acompañado de una pérdida de fuerza en el marco de las relaciones colectivas de trabajo, es decir, el sindicalismo (Rebelo, 2004: 43).

La corrosión de la estructura normativa que protege derechos sociales y laborales es una tendencia a nivel global: las reformas que perjudican a los trabajadores han ocurrido tanto en países industrializados, como Italia y España, ${ }^{5}$ como en regiones periféricas, como México y Brasil. ${ }^{6}$ No es raro que estas reformas sean tan graves y profundas que lleguen a violar derechos reconocidos en tratados y convenciones internacionales y que, por lo tanto, hayan ganado el reconocimiento de derechos humanos.

5. En Italia, «el país más flexible de Europa», la disciplina rígida fue sustituida por la flexibilización que se desarrolla de manera desordenada, segmentada y sin reglas, eliminando los costos del trabajo y las garantías laborales (Vasapollo, 2006: 51). En España, a principios de 2012 se aprobó una reforma laboral bastante criticada por los sindicatos y los partidos opositores. A pesar de la promesa de modificar el mercado de trabajo para mejor, mediante la generación de empleos y la modernización de la demanda laboral, el diagnóstico de sus efectos tras cinco años de su aprobación revela el aumento de la precarización y la pobreza.

6. En México, fue la crisis económica de 2009 el gancho para el surgimiento del denominado Pacto por México, un programa del gobierno de Enrique Peña Nieto que incluía 95 compromisos en los más diversos campos (económicos, políticos y sociales) y abría camino para el establecimiento de reformas estructurales que supuestamente traerían crecimiento económico. Las reformas prometidas eran, en realidad, una profundización de la agenda neoliberal: privatizaciones, austeridad fiscal, fin del monopolio estatal para la explotación petrolífera, además de numerosas reformas en sectores estratégicos de la sociedad, incluso una sensible flexibilización laboral que pasó en el Congreso en 2013 (Guillén, 2015). Después de tres años de la aprobación de la reforma laboral mexicana, los datos divulgados por el Instituto Nacional de Estadística y Geografía a través de la Encuesta Nacional de Ocupación y Empleo revelan que la reforma contribuyó más a la desigualdad y a la vulnerabilidad de la población de bajos ingresos, y muy poco a la formalidad, a la productividad y a la generación de empleos. El actual momento brasileño es bastante similar al caso mexicano. Afectado por una crisis económica, el país registró recientes caídas en su producto interno bruto, lo que motivó la eclosión de una serie de «reformas» para supuestamente aumentar el crecimiento económico. Las reformas prometidas son una profundización de la agenda neoliberal por medio de privatizaciones, austeridad fiscal, reforma de la seguridad social y una enorme reforma laboral aprobada en el Congreso Nacional en tiempo récord. 
Es necesario resaltar que todo derecho humano, incluso el derecho humano laboral, es merecedor de respeto, promoción y protección, no importa si de ello se deriva una obligación de abstención o de prestación. Si el deber de respeto y promoción deriva para el Estado y sus agentes la prohibición de actuar de forma confrontacional a los derechos humanos y la adopción de acciones para permitir que los mismos sean ampliamente reconocidos, de la incumbencia de protegerlos se desprende una serie de obligaciones específicas relacionadas con la prevención y la represión de su violación.

En efecto, en el ejercicio del deber de protección, el papel del Estado va más allá de la concreción de normas reguladoras de las relaciones para asegurar en estas últimas la observancia de los derechos humanos (Gomes Canotilho, 2003: 409): le corresponde prevenir, cohibir y sancionar la ocurrencia de cualquier afrenta a estos derechos, sea por parte del poder ejecutivo, mediante la adopción de medidas administrativas, sea por el poder legislativo, por medio de la edición de leyes punitivas, sea, todavía, a través del sistema de justicia, responsable de la realización de investigaciones, juicios e imposición de sanciones (Beltramelli Neto, 2017: 40-41). Y aquí reside el denominado «control de convencionalidad» de las leyes, ${ }^{7}$ como medida específica de protección de los derechos humanos.

Durante el proceso de producción de leyes, al legislador le incumbe salvaguardar los derechos humanos mediante el análisis de la conformidad de la norma con los tratados y convenciones internacionales. Sin embargo, si el poder legislativo se aleja de su obligación de servir a la promoción y protección de los derechos humanos y pasa a confrontarlos, los demás agentes del Estado deben adoptar las medidas necesarias para hacerlos efectivos, reprimiendo las violaciones provocadas por el proceso legislativo. En el caso concreto, surge el control difuso de convencionalidad de las leyes a cargo de los jueces y tribunales brasileños, a quienes corresponde el análisis de compatibilidad de las leyes y demás actos normativos con los tratados y convenciones internacionales de derechos humanos.

Por lo tanto, es el poder judicial que realiza, a la luz del caso concreto, el examen de conformación de determinado acto normativo doméstico con las normas internacionales de derechos humanos, dejando de aplicarlo en caso de incompatibilidad. Se trata de un deber derivado del principio de la supremacía convencional (CIDH, 2010), y así ha decidido la jurisprudencia brasileña:

La previsión contenida en el artículo 193, sección 2, de la Consolidación de las Leyes de Trabajo no fue aceptada por la Constitución Federal de 1988, que, en su

7. Se debe llamar el «control de constitucionalidad» sólo el estricto caso de incompatibilidad vertical de las leyes con la Constitución, y de «control de convencionalidad» los casos de incompatibilidad legislativa con los tratados de derechos humanos en vigor en el país (Oliveira Mazzuoli, 2016: 244). 
artículo 7, 23, garantizó de forma plena el derecho a la recepción de los adicionales de penosidad, insalubridad y peligrosidad, sin ninguna salvedad en lo que se refiere a la acumulación aunque haya remitido su regulación a la ley ordinaria. La posibilidad de la aludida acumulación se justifica en virtud de que los hechos generadores de los derechos son diversos. No hay que hablar de doble sanción (bis in idem). En el caso de la insalubridad, el bien tutelado es la salud del obrero, teniendo en cuenta las condiciones nocivas presentes en el medio ambiente de trabajo; y la peligrosidad traduce una situación de peligro inminente que, una vez ocurrida, puede quitarle la vida al trabajador, siendo este el bien que se pretende proteger. La reglamentación complementaria prevista en el citado precepto de la Ley Mayor debe guiarse por los principios y valores esculpidos en el texto constitucional, como forma de alcanzar, efectivamente, la finalidad de la norma. Otro factor que sostiene la inaplicabilidad del precepto celetista es la introducción en el sistema jurídico interno de las Convenciones Internacionales 148 y 155, con estatus de norma materialmente constitucional o, al menos, supralegal, como decidido por el Supremo Tribunal Federal. La primera consagra la necesidad de actualización constante de la legislación sobre las condiciones nocivas de trabajo y la segunda determina que se tengan en cuenta los «riesgos para la salud derivados de la exposición simultánea a diversas sustancias o agentes». En este contexto, no hay más espacio para la aplicación del artículo 193, sección 2, de la Consolidación de las Leyes de Trabajo . Recurso de revista de que se conoce y que no procede. (TST-RR-1072-72.2011.5.02.0384 - $7^{\text {a }}$ Clase - Min. Rel. Claudio Brandão - jul. 24/o9/2014) Traducción de los autores.

El deber de protección de los derechos humanos a través del control difuso de convencionalidad ejercido por los jueces nacionales ha sido reconocido incluso por quien lo ejerce de forma concentrada, o sea, por los tribunales internacionales de derechos humanos que realizan el control de convencionalidad matriz, auténtico o definitivo (Carvalho Ramos, 2016: 427). La Corte Interamericana de Derechos $\mathrm{Hu}-$ manos afirma que los jueces y tribunales nacionales, como parte del aparato del Estado, deben velar por las disposiciones del derecho internacional para que no sean mitigadas por las leyes internas contrarias a su objeto y finalidad:

La Corte es consciente de que los jueces y tribunales internos están sujetos al imperio de la ley y, por ello, están obligados a aplicar las disposiciones vigentes en el ordenamiento jurídico. Pero cuando un Estado ha ratificado un tratado internacional como la Convención Americana, sus jueces, como parte del aparato del Estado, también están sometidos a ella, lo que les obliga a velar por los efectos de las disposiciones de la Convención para que no se vean mermadas por la aplicación de leyes contrarias a su objeto y fin, y que desde un inicio carecen de efectos jurídicos. En otras palabras, el poder judicial debe ejercer una especie de «control de convencionalidad» entre las normas jurídicas internas que aplican en los casos concretos y la Convención Americana sobre Derechos Humanos. En esta tarea, el poder judicial debe tener en cuenta no solamente el tratado, sino también la interpretación que 
del mismo ha hecho la Corte Interamericana, intérprete última de la Convención Americana. ${ }^{8}$

Además, según la decisión de la Corte, el control de la convencionalidad debe ser realizado ex officio por los jueces y tribunales domésticos en el ámbito de sus competencias y conforme a las normas procesales correspondientes:

Cuando un Estado ha ratificado un tratado internacional como la Convención Americana, sus jueces también están sometidos a ella, lo que les obliga a velar porque el efecto útil de la Convención no se vea mermado o anulado por la aplicación de leyes contrarias a sus disposiciones, objetivos y fines. En otras palabras, los órganos del poder judicial deben ejercer no solo un control de constitucionalidad, sino también «de convencionalidad» ex officio entre las normas internas y la Convención Americana, evidentemente en el marco de sus respectivas competencias y de las regulaciones procesales correspondientes. Esta función no debe quedar limitada exclusivamente por las manifestaciones o actos en cada caso concreto, aunque tampoco implica que ese control deba ejercerse siempre, sin considerar otros presupuestos formales y materiales de admisibilidad y procedencia de ese tipo de acciones. ${ }^{9}$

De acuerdo con la jurisprudencia de la Corte, la obligación de ejercer el control de la convencionalidad pertenece a los jueces, tribunales y órganos relacionados con la administración de la justicia en todos los niveles:

Este Tribunal ha establecido en su jurisprudencia que es consciente de que las autoridades internas están sujetas al imperio de la ley y, por ello, están obligadas a aplicar las disposiciones vigentes en el ordenamiento jurídico. Pero cuando un Estado es parte de un tratado internacional como la Convención Americana, todos sus órganos, incluidos sus jueces, también están sometidos a él, lo cual les obliga a velar por que los efectos de las disposiciones de la Convención no se vean mermados por la aplicación de normas contrarias a su objeto y fin. Los jueces y órganos vinculados a la administración de justicia en todos los niveles están en la obligación de ejercer ex officio un «control de convencionalidad» entre las normas internas y la Convención Americana, evidentemente en el marco de sus respectivas competencias y de las regulaciones procesales correspondientes. En esta tarea, los jueces y órganos vinculados a la administración de justicia deben tener en cuenta no solamente el tratado, sino también la interpretación que del mismo ha hecho la Corte Interamericana, intérprete última de la Convención Americana. ${ }^{10}$

8. Sentencia del caso Almonacid Arellano con Chile, Corte Interamericana de Derechos Humanos, 26 de septiembre de 2006, párrafo 124.

9. Sentencia del caso Aguado Alfaro y otros con Perú, Corte Interamericana de Derechos Humanos, 24 de noviembre de 2006, párrafo 128.

10. Sentencia del caso Cabrera García y Montiel Flores con México, Corte Interamericana de Derechos Humanos, 26 de noviembre de 2010, párrafo 225. 
En efecto, si es deber de los jueces y tribunales nacionales el examen de la obediencia del derecho interno a los derechos previstos y tratados y las convenciones incorporadas al ordenamiento jurídico interno, ejerciendo el denominado control difuso de convencionalidad, se impone al poder judicial laboral, por lo tanto, la obligación de proteger los derechos humanos de los trabajadores frente a eventuales reformas a la legislación laboral incompatibles con las normas internacionales relativas a las relaciones laborales, dejando de aplicarlas al caso concreto si están en conflicto.

\section{La prohibición de retroceso social y la inconvencionalidad de la reforma laboral brasileña, Ley 13.467/2017}

La denominada reforma laboral o Ley 13.467 de 13 de julio de 2017 ha provocado profundas discusiones con respecto a los efectos que producirá en las relaciones individuales y colectivas de trabajo. No por casualidad la nueva regla, aprobada en tiempo récord, altera sensiblemente la legislación laboral e impacta directamente en las condiciones de vida y de trabajo de la clase asalariada.

Si los debates doctrinales giran en torno, sobre todo, del análisis de los aspectos positivos y negativos previstos en el nuevo texto, la jurisprudencia debe posicionarse en relación con una cuestión prejudicial: su conformidad o disconformidad a la Constitución Federal y a las convenciones internacionales ratificadas por Brasil. Esto es porque la aplicación de las nuevas reglas exige, como se ha mencionado anteriormente, su adecuación al derecho internacional de los derechos humanos. En el particular, los autores del presente texto entienden que la nueva ley tiene vicios insanables y que no guardan armonía con las Convenciones de la Organización Internacional del Trabajo, debiendo tener su aplicación denegada por medio de control difuso de convencionalidad a ser realizado de oficio por la magistratura laboral.

La inconveniencia reside, ante todo, en la ilegitimidad de la reforma: el proyecto que le dio origen corrió a toda prisa en el Congreso Nacional y padece de amparo popular, pero fue elaborado sin debates y discusiones sociales. Además, tampoco los interesados participaron activamente de su elaboración.

Esta ilegitimidad viola los dispositivos normativos de la Organización Internacional del Trabajo contenidos en el artículo 2, 1 del Convenio 144, y en el artículo 7 de la Convención 154, ambos de carácter tripartito, que exigen amplia discusión mediante consultas públicas efectivas sobre los asuntos relacionados con las actividades de la Organización Internacional del Trabajo, inclusive la obediencia a sus convenciones y recomendaciones, y sobre las medidas adoptadas para estimular el desarrollo de la negociación colectiva.

Además de frustrar la efectiva participación de las entidades interesadas en las discusiones y en la elaboración del texto normativo, la reforma, que no constaba en el programa de gobierno que recibió la mayoría de los votos de los brasileños, fue 
propuesta inicialmente por un gobierno sin legitimidad y sin aprobación popular, lo que demuestra el rechazo, el disentimiento y la falta de anuencia social. Así lo expresa el enunciado 1 de la Segunda Jornada de Derecho Material y Procesal del Trabajo que tuvo lugar los días 9 y 10 de octubre de 2017 en Brasilia, y contó con la presencia de cientos de magistrados, fiscales, abogados y académicos del derecho del trabajo:

Control de convencionalidad de la reforma laboral, ausencia de consulta tripartita y de consulta previa a las organizaciones sindicales. i) Reforma laboral. Ley 13.467 / 2017. Incompatibilidad vertical con los convenios de la Organización Internacional del Trabajo. Ausencia de consulta tripartita. Ofensa al Convenio 144 de la Organización Internacional del Trabajo; ii) Ausencia de consulta previa a las organizaciones de trabajadores. Ofensa a la Convención 154 de la Organización Internacional del Trabajo, así como a los contenidos 1075, 1081 y 1082 del Comité de Libertad Sindical del Consejo de Administración de la Organización Internacional del Trabajo.

No bastaba el vicio formal, ya que la reforma, en su contenido, viola los derechos humanos laborales y fue considerada materialmente ilegítima en la Segunda Jornada de Derecho Material y Procesamiento del Trabajo: «La Ley 13.467/2017 es ilegítima, en los sentidos formal y material».

No hay duda de que la reforma laboral contraría la noción de trabajo decente de la Organización Internacional del Trabajo. En 1999, la expresión, acuñada en la designación en lengua inglesa, fue empleada oficialmente por la Organización Internacional del Trabajo durante la $87^{\mathrm{a}}$ Conferencia Internacional del Trabajo en 1999, lo que dio origen a un punto de convergencia de los objetivos estratégicos de la entidad: la promoción de los principios y derechos fundamentales en el trabajo establecidos en la Declaración de 1998; el empleo; la protección social; y el diálogo social (Organización Internacional del Trabajo, 1999). ${ }^{11}$ El trabajo decente se refiere al trabajo jurídicamente protegido que contribuye a la inclusión social de la persona trabajadora.

El trabajo decente presupone, en efecto, el absoluto respeto a la dignidad humana de la persona trabajadora por medio de la efectividad y de la protección de los derechos que le son más caros.

La promoción del trabajo decente es un objetivo prioritario en la agenda para el año 2030 de la Organización de las Naciones Unidas para el desarrollo sostenible. Este es un documento que consiste en un plan de acción que establece una agenda

11. «El concepto de trabajo decente expresa la síntesis del mandato histórico y de los objetivos estratégicos de la Organización Internacional del Trabajo, agencia especializada de las Naciones Unidas fundada en 1919: la promoción de las normas internacionales del trabajo, más y mejores empleos para hombres y mujeres, la extensión de la protección social y la promoción del tripartismo y del diálogo social. Esta noción fue formalizada por primera vez en la memoria presentada por el Director General de la Organización Internacional del Trabajo en la $87^{a}$ Reunión de la Conferencia Internacional del Trabajo celebrada en Ginebra en junio de 1999» (Abramo, 2010: 151-152). La traducción es de los autores. 
política amplia y universal a ser implementada de forma consciente en los próximos años y que pretende promover sociedades pacíficas, justas e inclusivas, libres del miedo y la violencia, hacia la paz universal, objetivos del desarrollo sostenible. Para alcanzar su octavo objetivo, se establecieron, entre otras, las siguientes metas: alcanzar tanto el empleo pleno y productivo como el trabajo decente para todas las mujeres y hombres, incluso para los jóvenes y las personas con discapacidad. Además, lograr una remuneración igual para trabajo de idéntico valor. Para el año 2020, se espera reducir sustancialmente la proporción de jóvenes sin empleo, educación o formación; tomar medidas inmediatas y eficaces para erradicar el trabajo forzoso, acabar con la esclavitud moderna y el tráfico de personas, y asegurar la prohibición y eliminación de las peores formas de trabajo infantil. Finalmente, para el año 2025 se espera acabar con el trabajo infantil en todas sus formas; proteger los derechos laborales y promover ambientes de trabajo seguros y protegidos para todos los trabajadores, incluidos los trabajadores inmigrantes, en particular para las mujeres inmigrantes y las personas con empleo precario.

La protección de los derechos laborales es, por lo tanto, una meta prioritaria de las Naciones Unidas para la promoción del trabajo decente a nivel global. Debe ser observada por todos los países, en particular por los que están en vías de desarrollo, cuyas estrategias y programas de gobierno deben salvaguardar a todos los trabajadores frente a la desprotección jurídica y del medio ambiente de trabajo inseguro e indigno.

Como se ve, la reforma laboral contraría las directrices de protección y promoción del trabajo decente establecidas por el orden internacional. En cuanto a las características subyacentes de la flexibilización y la desregulación de derechos laborales, la nueva legislación desprotege, precariza y transfiere los riesgos de la actividad económica para el trabajador, contrariando la propia lógica protectora del derecho del trabajo.

Son numerosas las innovaciones precarias que, en su conjunto, contradicen la noción de trabajo decente y protegido propugnado por la Organización Internacional del Trabajo y la Organización de las Naciones Unidas: la amputación del grupo económico laboral (artículo 2, Consolidación de las Leyes de Trabajo ), una figura cuya finalidad es la garantía del pago del crédito por cualquiera de las empresas favorecidas por el contrato de trabajo; la institución del trabajador que presta servicios con exclusividad y de forma continua sin perder su condición de autónomo (artículo 442-B, CLT), facilitando el fraude y la contratación sin la protección legal; el surgimiento del contrato intermitente (artículo 452-A, CLT), una modalidad en la cual el trabajador no dispone de horario fijo, no posee carga de trabajo previamente establecida y no cuenta con salario cierto al final del mes; la tarificación y limitación de la indemnización por daño extrapatrimonial (artículo 223-G, CLT), inviabilizando la efectiva reparación del mal causado; crea obstáculos a la equiparación e isonomía salarial (artículo 461, CLT), afrontando el derecho a la igualdad formal y material; per- 
mite la tercerización ampliada y sin límites, permitiendo la prestación de servicios por intermedio de terceros en cualquier actividad, incluso en la principal (artículo 5 , Ley 6.019 / 74), lo que viabiliza la concepción del trabajo humano como mercancía y contraría los preceptos del trabajo seguro; la prevalencia de lo negociado sobre lo legislado en relación con la jornada de trabajo, al descanso para reposo y alimentación y al encuadramiento del grado de insalubridad (artículo 611-A, CLT), cuestiones sobre la salud, higiene y seguridad del trabajo no permitidas, pues, a la negociación; la extinción de la contribución sindical obligatoria (artículo 579, CLT) que debilita significativamente las entidades sindicales representativas de la clase obrera; etcétera.

Las nuevas reglas, en su conjunto, contrarían la directriz evolutiva trazada por el Pacto Internacional sobre Derechos Económicos, Sociales y Culturales, que impone a los Estados partes la adopción de medidas encaminadas a asegurar, «progresivamente» y por todos los medios apropiados, el pleno ejercicio de los derechos en él previstos, especialmente en la esfera legislativa (artículo 2, 1).

La expresión «progresivamente», prevista en el artículo 2 del pacto, tiene la meta de enfatizar la necesidad de que los Estados adopten las medidas en él previstas para realizar los derechos lo más rápido posible, no pudiendo ser interpretada, jamás, como una potestad discrecional del Estado:

La expresión «aplicación progresiva» a menudo ha sido mal interpretada. En el comentario general, apartado 3, sobre la naturaleza de las obligaciones estatales concernientes al artículo 2, párrafo 1, el Comité de Derechos Económicos, Sociales y Culturales afirmó que si la expresión «realización progresiva» constituye un reconocimiento del hecho de que la plena realización de los derechos económicos, sociales y culturales no puede alcanzarse en un corto período de tiempo, esta expresión debe interpretarse a la luz de su objetivo central, que es establecer claras obligaciones a los Estados partes para adoptar medidas lo antes posible, para la realización de estos derechos (General Comment, apartado 3, UN doc. E/1991/23) (Piovesan, 2006: 70) Traducción de los autores.

El referido instrumento internacional presenta la idea de prohibición de retroceso, lo que significa impedir que las conquistas de positivización jurídica relativas a derechos sociales sean suprimidas o disminuidas por medidas que puedan, en todo caso, desfavorecer el progreso y el avance social. Se trata de una directriz que orienta al poder público a no alterar perjudicialmente las conquistas sociales, dándoles un cierto grado de seguridad jurídica y estabilidad.

La razón de este principio de progresividad y prohibición de retroceso es que los gobiernos tienen la obligación de asegurar, consistente y gradualmente, todos los derechos sociales reconocidos por los tratados y convenios internacionales, aplicando el máximo de recursos posibles hasta la implementación total de los mismos. Es decir, la progresividad abarca dos sentidos complementarios: gradualidad y progreso. 
El segundo aspecto se refiere a la obligación estatal de mejorar las condiciones de ejercicio de dichos derechos (Mazetto Ferreira, 2007: 68).

El alcance de la sociedad internacional es siempre acumular ventajas al plano nacional y, a través del esfuerzo continuo y conjugado de los Estados, propiciar el ininterrumpido incremento a la posición social y jurídica del trabajador en tanto matices de la persona humana (Muradas Reis, 2007). Como el propio nombre dice, el principio significa el deber de mejora continua, estando prohibido el retroceso social.

Además de previsto en normas internacionales, el principio de prohibición de retroceso social también fue positivizado en el texto constitucional brasileño. Específicamente en lo que concierne a los derechos laborales, existe una expresa previsión constitucional en cuanto a la progresividad de estos derechos en el artículo 7 , que prevé una cláusula de apertura a otros derechos de idéntica naturaleza que apunte a la mejora de la condición social de la persona trabajadora.

Los derechos humanos laborales están en jaque. Los magistrados y demás órganos vinculados a la administración de la justicia del trabajo deberán, más que nunca, ejercer el control difuso de convencionalidad en la protección del postulado de la dignidad humana y de los derechos que le son subyacentes.

\section{Conclusión}

La Ley 13.467, de 13 de julio de 2017, desobedece tratados y convenciones internacionales de los cuales Brasil es signatario y que establecen normas aplicables a las relaciones de trabajo universalmente reconocidas.

Desde el punto de vista formal, la reforma laboral contraría a los dispositivos previstos en el artículo 2, 1 del Convenio 144, y el artículo 7 de la Convención 154, ambos de la Organización Internacional del Trabajo, ya que el proyecto que le dio origen corrió a toda prisa en el Congreso Nacional y fue elaborado sin debates y discusiones sociales. Por otra parte, tampoco los interesados participaron activamente de su elaboración. Además, la nueva regla flexibiliza, desregula, desprotege y precariza, oponiéndose a la noción de trabajo decente propugnada por la Organización Internacional del Trabajo.

Además de violar formal y materialmente los derechos humanos laborales, la reforma contraría al principio de prohibición de retroceso social previsto en el Pacto Internacional de Derechos Económicos, Sociales y Culturales, que traza una directriz para el poder público en el sentido de no modificar perjudicialmente las conquistas sociales, incluyendo la evolución normativa relacionada con los derechos que le son subyacentes.

En efecto, si el legislador brasileño se desentendió de su obligación de salvaguardar los derechos humanos durante la realización del proceso legislativo y de la inno- 
vación en el mundo jurídico-laboral, los jueces y tribunales brasileños deben analizar la conformidad de la ley con los tratados y convenciones internacionales.

Actualmente, ante las reformas y retrocesos llevados a cabo por el legislativo con el sello del ejecutivo, corresponde al poder judicial ejercer el control difuso de convencionalidad para proteger y hacer efectivo el postulado de la dignidad humana. Se trata de una obligación del magistrado laboral derivada del principio de la supremacía convencional y del deber judicial de protección de los derechos humanos.

\section{Referencias}

Abramo, Laís (2010). «Trabalho Decente: o itinerário de uma proposta». Bahia Análise \& Dados, Salvador, 20 (2-3): 151-171. Disponible en https://bit.ly/2FxvusV.

Abrantes, José João (2005). Contrato de trabalho e direitos fundamentais. Coimbra Editora.

Beltramelli Neto, Silvio (2017). Direitos humanos. $4 .^{\mathrm{a}}$ ed. Salvador: Juspodivm.

Bezerra Leite, Carlos Henrique (2011). Direitos humanos. 2. ${ }^{a}$ ed. Río de Janeiro: Lumen Juris.

Cançado Trindade, Antônio Augusto (1997). Tratado de Direito Internacional dos Direitos Humanos. Tomo I. Porto Alegre: Sérgio Antonio Fabris.

Carvalho Ramos, André de (2016). Curso de direitos humanos. 3. ${ }^{\mathrm{a}}$ ed. São Paulo: Saraiva.

Correa, Eugenia (2013). «Hacia una política de pleno empleo en México». En Alicia Girón, Antonina Ivanova, Arturo Guillén y Eugenia Correa (coordinadores), Estrategias para un Desarrollo Sustentable (pp. 365-380). México: Miguel Ángel Porrúa.

Gomes Canotilho, José Joaquim (1998). Direito Constitucional e teoria da Constituição. Coimbra: Almedina.

-. (2003). Direito constitucional e teoria da constituição. 7. ed. Coimbra: Almedina.

Guamán Hernández, Adoración y Héctor Illueca Ballester (2012). El huracán neoliberal: Una reforma laboral contra el Trabajo. Madrid: Sequitur.

GuILlÉN, Arturo (2015). "The "mexican moment": la economía mexicana en el marco de la crisis global». En Gregorio Vidal (coordinador), Estados Unidos, Europa, Asia, América Latina. La crisis va y se generaliza (pp. 205-229). México: Miguel Ángel Porrúa.-

LAfer, Celso (2005). A Internacionalização dos Direitos Humanos: Constituição, Racismo e Relações Internacionais. Barueri: Manole.

Leite Sampaio, José Adércio (2010). Direitos fundamentais: retórica e historicidade. 2. ${ }^{a}$ ed. Belo Horizonte: Del Rey.

Mazetto Ferreira, Lauro Cesar (2007). Seguridade social e direitos humanos. São Paulo: LTr. 
Muniz Cavalcanti, Tiago (2016). Neoabolicionismo e direitos fundamentais. São Paulo: LTr.

Muradas Reis, Daniela (2007). Contributo ao Direito Internacional do Trabalho: a reserva implícita ao retrocesso sociojurídico do trabalhador nas convenções da Organização Internacional do Trabalho. Tese Doutorado. Universidade Federal de Minas Gerais. Belo Horizonte: Faculdade de Direito.

Organización Internacional del Trabajo (1999). Conferência Internacional do Trabalho. $87^{\mathrm{a}}$ reunião. Genebra. Disponible en http://bit.ly/2 $\mathrm{HMaQH}_{3}$.

Oliveira Mazzuoli, Valério de (2016). Curso de Direitos Humanos. $3 .^{\mathrm{a}}$ ed. Río de Janeiro: Forense.

Paula Amaral, Júlio Ricardo de (2007). Eficácia dos direitos fundamentais nas relações trabalhistas. São Paulo: LTr.

Pérez Luño, Antonio E. (2013). Los derechos fundamentales. 11. ${ }^{a}$ ed. Madrid: Tecnos.

Piovesan, Flávia (2006). Direitos Humanos e o Direito Constitucional Internacional. 7. ed. São Paulo: Saraiva.

Rebelo, Glória (2004). Flexibilidade e precariedade no trabalho: análise e diagnóstico. Lisboa: Fundação para a Ciência e a Tecnologia.

ReZek, Francisco (2007). Direito Internacional Público - Curso Elementar. 10. ${ }^{a}$ ed. São Paulo: Saraiva.

Serrano Nunes Júnior, Vidal (2009). A cidadania social na Constituição de 1988: estratégias de positivação e exigibilidade judicial dos direitos sociais. São Paulo: Verbatim.

Sousa Santos, Boaventura de (2017). «Más allá de la imaginación política y de la teoría crítica eurocéntricas». Revista Crítica de Ciências Sociais, 114: 75-116. DOI: $10.4000 /$ rccs. 6784 .

VASAPOLlO, Luciano (2006). «O trabalho atípico e a precariedade: elemento estratégico determinante do capital no paradigma pós-fordista». En Ricardo Antunes (organizador), Riqueza e miséria do trabalho no Brasil (pp. 45-58). São Paulo: Boitempo.

Wolfgang SARLet, Ingo (2004). Dignidade (da pessoa) humana e direitos fundamentais na Constituição Federal de 1988. 3. ${ }^{a}$.ed. Porto Alegre: Livraria do Advogado.

\section{Sobre los autores}

Tiago Muniz Cavalcanti es profesor del curso de especialización en Derechos Humanos y Trabajo de la Escola Superior do Ministério Público da União. Estudiante de doctorado en Derecho del Trabajo por la Universidade Federal de Pernambuco con actividades de investigación en el Centro de Estudos Sociais de la Universidade de Coimbra en Portugal. Maestro en Derecho del Trabajo por la Pontifícia Universidade 
Católica de São Paulo. Especialista en Derecho Material y Procesal del Trabajo. Fiscal laboral.

Juliana Teixeira Esteves es profesora de la graduación y posgrado en la Facultad de Derecho de la Universidade Federal de Pernambuco. Además, es maestra en Ciencia Política y doctora en Derecho por la Universidade Federal de Pernambuco. También tiene un posdoctorado en curso en el IRES/FRANCE. Líder del grupo de investigación «Direito do Trabalho e Teoria Social Crítica» y colíder de «Direito e Política». Abogada, presidente de la Academia Pernambucana de Direito do Trabalho y vicepresidente del Instituto Ítalo-Brasileiro de Direito do Trabalho. 
La Revista Chilena de Derecho del Trabajo y de la Seguridad Social es una publicación semestral del Departamento de Derecho del Trabajo y de la Seguridad Social de la Facultad de Derecho de la Universidad de Chile, y que tiene por objetivo el análisis dogmático y científico de las instituciones jurídico-laborales y de seguridad social tanto nacionales como del derecho comparado y sus principales efectos en las sociedades en las que rigen.

\author{
DIRECTOR \\ Luis Lizama Portal \\ EDITOR \\ Claudio Palavecino Cáceres \\ SECRETARIO DE REDACCIÓN \\ Eduardo Yañez Monje \\ SITIO WEB \\ revistatrabajo.uchile.cl \\ CORREO ELECTRÓNICO \\ pyanez@derecho.uchile.cl \\ LICENCIA DE ESTE ARTÍCULO \\ Creative Commons Atribución Compartir Igual 4.o Internacional
}

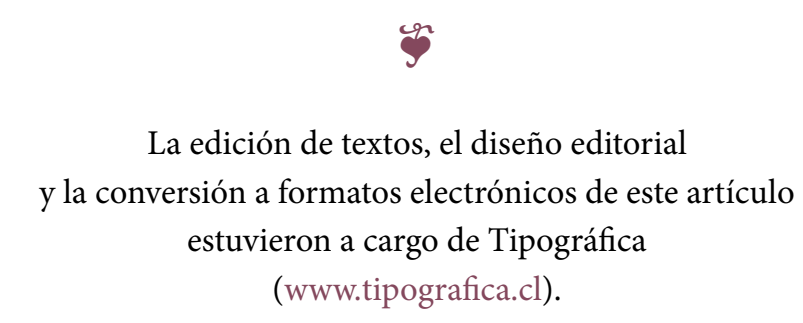

